\title{
An Assessment of Socio-Economic Factors on Nutritional Status in Primary School - A Cross

$$
\text { Sectional Study in Purulia of West Bengal }
$$

\begin{abstract}
:
Background: Child malnutrition is one of the most vital global health problems concerning in most of the poor communities leading to high morbidity and mortality. Various studies have highlighted the relationship between socioeconomic status and nutrition levels of primary school children. The present study focuses on socioeconomic inequality resulting in risk of malnutrition. Objectives of the Study were to find the Impact of socio-economic factors on nutritional status in primary school children. Methods: A cross sectional survey of 281 children, aged 6-10 years were selected from remote primary school in Purulia were used in the study. the primary schools were randomly selected. The studied variables included; Age, sex of the pupils, parents' socio-economic status and family size of selected House Holds. Interview of pupils and parents was carried out using prepared Nordic questionnaire template. Weight and height of the children were measured. and Body Mass Index (BMI) was calculated by standard method. Data was analyzed using Microsoft excel, SPSS version 8.0 .The chi-square significance of association was determined at Level of significance less than 0.05 . Results: The proportion of girls and boys are $55.8 \%$ and $44.2 \%$ respectively. The nutritional status of children from lower socio economic class was poor as compared to their counter parts came from upper socio economic class. Children with BMI $<5$ th percentile were $30.9 \%$ in low class while in high class it was only $12.1 \%$. Prevalence of malnutrition was $41.9 \%$ among children of family size $>4$ as compare to $16.4 \%$ in those of House Holds had family size $<5$. During comparison of the studied children with children of same age group of overall West Bengal from NNMB survey, 2002, the first group had lower BMI than the second group. Conclusion: Poverty, low literacy rate, large families, food insecurity, food safety, appears to be the important factors responsible for poor health status of children from low socioeconomic class. Efforts should be given for exploring knowledge about nutritional needs during childhood, and creating nutritional and health awareness among young rural children to ensure a better quality of life for the next generation.
\end{abstract}

Key Words: Body Mass Index, Underweight, Socioeconomic Class, Nutrition, Children, Primary School

\section{Introduction}

Growth is at its peak during the school age, there are a number of changes take place with which they have to cope with. The nature of the children's growth depends upon nutritional status and environmental condition, which interacts with other socioeconomic, bio-physiological, and physical environmental factors. ${ }^{1}$ The children from households with a low or very low socioeconomic status had 2.5 times the risk of being underweight relative to children who came from households with middle to upper socioeconomic status. ${ }^{2}$ Children from better socioeconomic classes would naturally have better nutrition and better environment. ${ }^{3}$ Low levels of nutrition adversely affect physical and mental growth of children. Malnutrition is one of the most important global health problems, affecting large numbers of children in developing Countries. ${ }^{4}$ In developing countries it is
Dimpal Arora ${ }^{1}$, Subrata Datta ${ }^{2}$ and Soudeep $\mathrm{Kr} \mathrm{Sau}{ }^{3}$

${ }^{1}$ Department of Physiology, C.M. Medical College, Kachandur, Durg 2 Ergonomics and Sports Physiology Division, Department of Human Physiology with community Health, Vidyasagar University, Midnapore-721 102, WB.

3Department of Physiology, Rungta College of Dental Sciences and Research, Kokha-Kurud Road, Bhilai

Corresponding Author: Dr. Subrata Datta Email: subrata.mid10@gmail.com

(c) 2014 IJOSH All rights reserved. postulated that poverty and ignorance are primary casual factors of malnutrition. ${ }^{5}$ Malnutrition and under nutrition significantly deal with physical, physiological and mental suffering and it is obvious a violation of a child's human rights. Malnutrition substantially raises the risk of infant and child deaths, and increases vulnerability to a variety of diseases in later life. Both prevalence and the severity of food insecurity increase as household incomes decrease. ${ }^{6}$ The type and quantity of various foods is based on socio-culture and economic considerations. ${ }^{7}$ In South Africa, the study revealed childhood malnutrition is the result of low income of Households. ${ }^{8}$ There are various factors both social and economic which affect child nutrition which manifest itself as poor development. In spite of India's rapid economic growth, there has been a sustained decline in per capita calorie consumption during the last twenty-five years. ${ }^{9}$ Inadequate food 
habits along with traditional socio-cultural and biological activities may lead to high proportion of child under nutrition. ${ }^{10,11}$

The Body Mass Index (BMI) is an index of weight adjusted for stature. It is one of the useful tools for diagnosing obesity or malnutrition; however, such diagnosis should take into account a person's age, gender, fitness, and ethnicity. For example, Asian populations may require a lower BMI to describe health risk, while Pacific populations, specifically Hawaiian, may require a higher threshold or higher level of BMI to indicate that an individual is at risk. ${ }^{12}$ The 2008 Egyptian Demographic and Health Survey (EDHS) showed that 5 percent of males and 3 percent of females aged from 10 - 19 in Egypt were considered to be underweight, i.e., their BMl values fell below the $5^{\text {th }}$ percentile on the age and sex-specific BMI growth charts. ${ }^{13}$

In view of all above mentioned aspects, the present investigation was studied on rural children of primary school at remote areas. The main objective was to analyze the socio economic factors like gender, income, family size, and their impact on nutritional status of children.

\section{Methods}

\section{Study Population and Sampling}

The present study was carried out in the 9 rural primary schools, located at remote areas of Baghmundi-II Circle in Purulia District. All children had the age between 6 to 10 years. All students were explained the objectives of the study by one of the authors. An informed consent in writing was obtained from all those students who agreed to participate in the study. Two hundred eighty three primary school students finally participated. Out of 283 children studied, there were 158 (55.8\%) girls, and 125 (44.2\%) boys. Data was collected during August to December 2014. The family is classified as High when income lies above Mean $+1 / 2$ SD $>$ Rs $11000 /-$, medium, when income lies between Rs 7555and Rs 10999 per month and low when income lies below (Mean $-1 / 2$ SD, i.e., < Rs 5000/ per month. ${ }^{14}$ The criterion set for assessing nutrition status in this study was BMI for age in relation to the growth chart of National Centre for health statistics reference population. Different body dimensions of the subjects were taken by means of anthropometer (Holtain), sliding caliper and steel tape by adopting proper landmark definition ${ }^{15}$ and standard measuring techniques. ${ }^{16}$ The all data were taken with the mean of three consecutive trials. The following anthropometric measurements were taken:

Weight: The body weight of the subjects was measured by portable weighing machine. All subjects were asked to wear shorts and banian and were bare footed during measurements.

Height: The vertical distance from the standing surface to the top was measured by anthropometric rod.

BMI: In this study different growth patterns of the children of different age groups were evaluated though their cross sectional data. Body weight $(\mathrm{Kg})$ of a subject dividing by the squared value of his height (meter), body mass index was calculated.

Body mass index (B.M.I. $)=$ Weight $(\mathrm{Kg}) /{\text { Height }(\text { meter })^{2}}^{2}$
BMI is a very useful approximation to what one should weigh depending on height in children and teens. Body mass index is used to assess underweight, overweight, and risk for overweight.

To identify the causative factors on the nutritional status of the primary school children, data analysis had been made with the help of a software package on 'STATISTICA' (Version 8.0) and test of significance used was Chi-Square.

\section{Ethical Consideration:}

Approval was obtained from the schools authorities prior to the commencement of the research. The teachers, students, and parents were well-informed of the scope and extent of the survey. All students were explained the objectives of the study by one of the authors. Verbal consents were obtained from all those students who agreed to participate in the study.

\section{Results}

In Table-1, the frequency and percentages of socio-economic status of 283 House Holds is presented. Among the 283 studied House Holds, 152 (53.7\%) House Holds were selected who belonged from lower socioeconomic status and had par capita monthly income < Rs 5000/ per month. The average per capita monthly income was Rs.3781. The $34.6 \%$ House Holds were in median economic class. From the Table-1, it was also revealed that the girls were belonged from higher percentage $(60.8 \%)$ of House Holds of lower socioeconomic class. The lower socioeconomic status of the families might be related to the paucity of income sources, low wage rate, poor communication system, higher family size, etc.

Table I Frequency distribution by socioeconomic class

\begin{tabular}{|ccc|}
\hline $\begin{array}{c}\text { Socio Economic } \\
\text { Class }\end{array}$ & Girls $(\mathrm{n}=158)$ & Children \\
\hline High & $18(11.4 \%)$ & $15(12.0 \%)$ \\
\hline Median & $44(27.8 \%)$ & $54(43.2 \%)$ \\
\hline Low & $96(60.8 \%)$ & $56(44.8 \%)$ \\
\hline
\end{tabular}

Table II Impact of socioeconomic class on nutritional status

\begin{tabular}{|c|c|c|c|c|c|c|}
\hline \multirow{2}{*}{ BMI for Age } & \multicolumn{2}{|c|}{ Low class } & \multicolumn{2}{|c|}{ Median class } & \multicolumn{2}{|c|}{ High class } \\
\hline & Girls & Boys & Girls & Boys & Girls & Boys \\
\hline$<5^{\text {th }}$ percentile & 33 & 14 & 12 & 17 & 3 & 1 \\
\hline $\begin{array}{l}5^{\text {th }}-85^{\text {th }} \\
\text { percentile }\end{array}$ & 52 & 26 & 17 & 15 & 2 & 8 \\
\hline $\begin{array}{l}85 \text { th- } 95^{\text {th }} \\
\text { percentile }\end{array}$ & 9 & 11 & 9 & 13 & 10 & 5 \\
\hline$\geq 95^{\text {th }}$ percentile & 2 & 5 & 6 & 9 & 3 & 1 \\
\hline Total & 96 & 56 & 44 & 54 & 18 & 15 \\
\hline
\end{tabular}

Among children from high socio-economic class only 8 (24.2\%) were under-nourished, $9(27.3 \%)$ had satisfactory nutritional status and $12(36.4 \%)$ were at risk of being overweight, and 4 $(12 \%)$ were obese. The higher percentage $(32.7 \%)$ of children in 
median socio-economic class was observed with satisfactory nutritional status. In children from low socioeconomic class, 47 $(30.9 \%)$ were underweight, nutritional status of $78(51.3 \%)$ children was satisfactory, and $20(13.2 \%)$ were at risk of being overweight. Only 7 (4.6\%) were obese. It was also found that in low socioeconomic class, the underweight girls had greater percentage $(9.4 \%)$ than the boys of same class. The results were statistically significant $(p<0.05)$ (Table-2).

\section{Table III Impact of family size on nutritional status}

\begin{tabular}{|c|c|c|c|c|c|c|c|c|c|c|}
\hline \multirow{3}{*}{$\begin{array}{l}\text { BMI for } \\
\text { Age }\end{array}$} & \multicolumn{10}{|c|}{ Family Size } \\
\hline & \multicolumn{2}{|c|}{3} & \multicolumn{2}{|c|}{4} & \multicolumn{2}{|c|}{5} & \multicolumn{2}{|c|}{6} & \multicolumn{2}{|c|}{$>7$} \\
\hline & $\frac{\rho}{\frac{7}{m}}$ & 兽 & $\frac{\rho}{\frac{7}{6}}$ & $\sum_{\infty}^{\infty}$ & $\frac{\rho}{\frac{7}{n}}$ & $\sum_{0}^{\infty}$ & $\frac{\rho}{\bar{T}}$ & $\sum_{0}^{\infty}$ & $\stackrel{?}{\frac{P}{\omega}}$ & 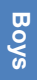 \\
\hline $\begin{array}{c}<5^{\text {th }} \\
\text { percentile }\end{array}$ & 2 & 2 & 4 & 4 & 12 & 7 & 19 & 11 & 11 & 8 \\
\hline $\begin{array}{l}5^{\text {th }}-85^{\text {th }} \\
\text { percentile }\end{array}$ & 6 & 5 & 4 & 13 & 17 & 9 & 27 & 15 & 16 & 8 \\
\hline $\begin{array}{l}85^{\text {th }}-95^{\text {th }} \\
\text { percentile }\end{array}$ & 4 & 2 & 7 & 7 & 6 & 6 & 8 & 11 & 4 & 2 \\
\hline $\begin{array}{c}\geq 95^{\text {th }} \\
\text { percentile }\end{array}$ & 3 & 3 & 4 & 3 & 1 & 1 & 2 & 5 & 1 & 3 \\
\hline Total & 15 & 12 & 19 & 27 & 36 & 23 & 56 & 42 & 32 & 21 \\
\hline
\end{tabular}

Table III Comparison of different anthropometric dimensions of studied children and children of all over West Bengal.

\begin{tabular}{|c|c|c|c|c|}
\hline Sex & & $\begin{array}{c}\text { Standing } \\
\text { height }(\mathrm{cm})\end{array}$ & Weight (kg) & BMI $\left(\mathrm{Kg} / \mathrm{m}^{2}\right)$ \\
\hline \multirow{3}{*}{ Girls } & $\begin{array}{l}\text { Studied } \\
\text { children }\end{array}$ & $\begin{array}{l}116.03 \\
\pm 6.47\end{array}$ & $16.72 \quad \pm 3.42$ & $12.59 \pm 3.21$ \\
\hline & $\begin{array}{l}\text { West Bengal } \\
\text { children }\end{array}$ & 114.35 & 17.73 & 13.37 \\
\hline & $\begin{array}{c}\text { Mean } \\
\text { difference }\end{array}$ & 1.68 & -1.01 & -0.78 \\
\hline \multirow{3}{*}{ Boys } & $\begin{array}{l}\text { Studied } \\
\text { children * }\end{array}$ & $\begin{array}{l}119.47 \\
\pm 3.67\end{array}$ & $17.65 \quad \pm 2.36$ & $12.86 \pm 4.22$ \\
\hline & $\begin{array}{l}\text { West Bengal } \\
\text { children }{ }^{\#}\end{array}$ & 114.95 & 17.93 & 13.66 \\
\hline & $\begin{array}{c}\text { Mean } \\
\text { difference }\end{array}$ & 4.52 & -0.28 & -0.8 \\
\hline
\end{tabular}

From Table-3, it was observed that about $41.9 \%$ children from family size more than 4 had BMI value less than 5 th percentile $(p<0.05)$ whereas $16.4 \%$ children were undernourished when the family size was $<5$. BMI values were negatively correlated to family size $(p<0.05)$. The children from family size $>4$ was 3 times more likely to have state of under nutrition compare to family had three to four siblings $(\mathrm{OR}=3.66 ; 95 \% \mathrm{Cl}=1.81-7.43, \mathrm{p}>$ $0.000)$. The prevalence of underweight was highest in families of more than 5 members. ${ }^{17}$ However no significant difference was observed with respect to gender of the siblings.
From the Table-4, different antropometric dimensions of Bengalee primary school children are compared with the Indian rural boys. From the table, it has been observed that standing height was higher but weight was lower in Studied rural children than West Bengal rural children. But the BMI is slightly lower in Studied primary school children than West Bengal children of same age group (6-10 years).

\section{Discussion}

From the above results, the nutritional deficiencies as well as nutritional inadequacies are never be overlooked but the problems are rooted in different sectors of social manifestations such as family income, availability of foods, education, awareness etc. Under nutrition is one of the byproduct of poverty, insufficient education, ignorance, low income, large family size, occupation, etc. family size and household income showed statistically significant association with childhood malnutrition. In this study, it was clearly revealed that percentage of children from high socioeconomic as well as small families had significantly higher BMI $(p<0.05)$ as compared to low socioeconomic and large families. Children from large household were significantly shorter and consumed diet of poor quality as assessed by intake of food from Animal sources.

However, children studied in present study were not enough to draw a definite conclusion. Deprivation of adequate food supplement is found in large families. From the existing evidence, it is clear that childhood malnutrition is associated with a number of socioeconomic and environmental characteristics such as poverty, parents' education/occupation, and access to health care services. ${ }^{19.20}$

\section{Conclusion}

In the light of the above discussion, it is necessary to discuss some strategies required for improving the nutritional status of our children. Low levels of nutrition among children cause serious long and short-term consequences in their physical and mental growth. Studies report high levels of mortality among malnourished children. ${ }^{21}$ Further, malnourished children are more likely to have functional impairment in adult life ${ }^{22}$ leading to a reduction in productive life and thus affecting the overall economic productivity of the society. ${ }^{22}$ Finally, it cannot be denied that formulating appropriate programmes and strategies are essential but effective implementation should be done. Efforts are necessary for exploring knowledge about nutritional needs during childhood, and creating nutritional and health awareness among young rural children to ensure a better quality of life for the next generation.

\section{References}

1. Zanvar V, Devi R. Influence of educational and occupational status of parents on anthropometric measurements of selected adolescent girls. J Daiying Foods H.S. 2007, 26(1): 23-32. 
2. Kikafunda JK, Walker AF, Collett D, Tumwine JK. Risk Factors for Early Childhood Malnutrition in Uganda. Pediatrics. 1998, 102(4):e45.

3. I.C.M.R., 1989, Growth and Physical development of Indian infants and children. Technical report series no. 18, Indian Council of Medical Research, New Delhi.

4. Filiz E, Pýnar O, Gonc, A, Erdal, BE. Nutritional Status and Risk Factors of Chronic Malnutrition in Children under Five Years of Age in Aydýn, a Western City of Turkey. Turkish Journal of Pediatrics. 2007, 49: 283-289.

5. Odunayo SI, Oyewole AO. Risk Factors for Malnutrition among Rural Nigerian Children. Asia Pacific Journal of Clinical Nutrition. 2006, 15: 491-495.

6. Carlson SJ, Andrews MS, Bickel GW. Measuring food insecurity and hunger in the United States: development of a national benchmark measure and prevalence estimates. J Nutr. 1999, 129(2S Suppl): 510S-516S.

7. Gopalan C, Rama Sastri BV, Balasubramanian SC. Nutritive value of Indian foods. National Institute of Nutrition, Indian Council of Medical Research. Hyderabad 2004.

8. Griffith P, Mathews, Hinde A. Gender, Family and the Nutritional status of Children in three culturally contrasting states of India. Social Science and Medicine. 2002, 55:755-790

9. Deaton. Nutrition in India- Facts and Interpretations Subal Das and Kaushik Bose 2011-Assessment of Nutritional Status by Anthropometric Indices. 2008.

10. Balgir RS, Kerketta AS, Murmu B et al. Clinical assessment of health and nutritional status of Gond children in Kalahandi district of Orissa. Indian J Nutri Dietet. 2002, 39:31-37.

11. Rao MK, Kumar RH, Venkaiah $\mathrm{K}$ et al. Nutritional status of Saharia-A primitive tribe of Rajasthan. J Hum Ecol. 2006, 19:117-123.

12. Hattiwale HM, Maniyar SA, Das KK, Dhundasi SA. Role of body mass index on physical fitness index in two different age groups of healthy young males from north interior Karnataka, India. Al Ameen J Med Sci. 2008, 1(1): 50-54.

13. El-Zanaty F, Way A. Egypt Demographic and Health Survey 2008. Demographic and Health Surveys, Ministry of Health, Cairo 2009.

14. Stany D'Souza, Sheela AM, Raja JD. Impact of Socioeconomic Factor on Chilld Development among Urban PoorA Study in Bangalore, Rev. European Scientific Journal August. 2013, 9 (23).

15. Ermacova SV, Podstavkina TP, Strokina AN. Anthropometric Atlas, Recommendation of methods. New Delhi: Amerind publishing Co.Pvt. Ltd 1985.

16. Weiner, JS and Lourie, JA. 1969, Human Biology: A guide to field methods, IBP Hand Book No.9 Blackwell Scientific Publications, Oxford.
17. Mukherjee R, Chaturvedi S, Bhalwar R, Determinants of Nutritional Status of School Children MJAFI. 200864 : 227231.

18. NNMB. Diet and Nutritional Status of Rural Population. Technical Report No.21, National Nutrition Monitoring Bureau, Hyderabad 2002

19. Vella V, Tomkins A, Borghesi A, Migliori GB, Adriko BC, Crevatin $E$. Determinants of child nutrition in north-west Uganda Bul World Health Organ 1992;70:637-47.

20. Pelletier D, Frongillo Jr EA, Habicht JP. Epidemiologic evidence for a potentiating effect of malnutrition on child mortality. Am J Public Health 1993; 83:1130-33.

21. A critical link. Interventions for physical growth andpsychological development: a review. Geneva, World HealthOrganization, 1999. (WHO/CHS/CAH/99.3).

22. Smith L, Haddad N. Overcoming child malnutrition in developing countries: past achievement and future choices. Washington DC: International Food Policy Research Institute. 2000. 